\title{
Engineering students enhance their social skills by sharing their knowledge with Afro-Colombian
}

\author{
Forero- Peña Luz Amalia ${ }^{1,}{ }^{*}$, Leiva-Rojas Edna Ivonne ${ }^{2}$ and Ramírez-Pisco Ramiro ${ }^{3}$ \\ ${ }^{1}$ Assistant professor, Department of Forest Engineering, Universidad del Tolima, Ibagué, Colombia. \\ ${ }^{2}$ Associate profesor, Department of Agronomy, Universidad Nacional de Colombia, Medellín, Colombia. \\ ${ }^{3}$ Associate profesor, Geosciences, Universidad Nacional de Colombia, Medellín, Colombia.
}

Publication history: Received on 21 February 2020; revised on 07 March 2020; accepted on 09 March 2020

Article DOI: https://doi.org/10.30574/gscarr.2020.2.3.0011

\begin{abstract}
The challenge of sustainable development demands that intelligence quotient requirements are not enough for the successful future of engineers and similar professionals. It is necessary that students develop emotional intelligence to increase their ability to understand and communicate emotions, guide their thought process, and increase their capacity to solve difficulties. Engineering professionals working in rural development related to sustainable resource management are not being as effectual as they could be their work with communities is fragmented or incomplete as they have not been given support or advice regarding human development. In the current study a group of forest engineering students experienced complete immersion with a local community of Bajo Calima, during a field trip to Centro Forestal Tropical (Tropical Forestry Center TFC). The knowledge exchange that occurred between students and the community developed students' empathy for and understanding of the community's problems.
\end{abstract}

Keywords: Local knowledge; Scientific local; Dialogue; Empathy; Social learning

\section{Introduction}

Our society is characterized by continuously changing paradigms, and the development of technology companies, and professionals, that have been stimulated to strengthen their capacity to improve their performance in a competitive environment. Companies have understood that success is not only dependent on intellectual capacity or technical skills, but also dependent on social skills [1]. Similarly, it is recognized that not having people emotionally trained or prepared represents an ethical and monetary partition. In the past decade, media and education and research institutions have developed important roles in promoting and dispersing information about the importance of social skills and/or emotional intelligence.

In the professional environment including forest-engineering it is necessary to enrich the personal relationships that allows engineers to understand the needs and problems of people in rural areas in order to achieve results that contribute to their development and progress bases on knowledge. The presence of social skills that facilitate tolerance and end prejudices are even more important in diverse environments [2].

In order to identify and help develop the emotional / social skills for students of forestry engineering at the Universidad del Tolima (University of Tolima), an exploratory study was conduct-ed to evaluate the day-to-day experiences that integrate the skills, knowledge, and aptitudes of students with a rural local community from Bajo Calima, Buenaventura, Colombia. In this document, there is a compilation of the experiences and learned lessons of 245 students from the last semester of their professional studies. The participatory methodology allowed for the identification of social skills in

\footnotetext{
${ }^{*}$ Corresponding author: Forero- Peña Luz Amalia
} 
the students with empathy playing a key role in the completion of the study. Paragraph: use this for the first paragraph in a section, or to continue after an extract.

\subsection{Context}

Organizations permanently confront the need to improve their work performance to facilitate their competitiveness. For response to continuous changes, in current society, organizations are responding to a demand for efficiency making areas related to client service, teamwork, creativity development, and leadership important and visible for them.

Organizations need the development of skills and aptitudes that allow people to express their emotional intelligence that facilitate the understanding of the dynamics of communities in their physical, socio-cultural and economic environment, for joint work. Academia is not far away from this tendency. It has found in emotional skills a very important way to improve efficiency and performance of people and the professional adaptation to employment requirements and demands $[3,4]$.

The emotional intelligence concept is ubiquitous. UNESCO [5] launched a world initiative and sent 140 education ministries a declaration containing 10 basics to implement learning for social and emotional programs that encourage the development of emotional skills. For in-stance, self-control, enthusiasm, empathy, perseverance, and the capacity to encourage one-self are skills capable of being learned and enhanced during a lifetime of experiences if appropriate methods are implemented [2].

Gardner [6] declared that besides a cognitive intelligence there are another seven distinct capabilities where two types of personal intelligence must be highlighted: the interpersonal that allow individuals to understand others and the intrapersonal that allow people to be self-aware. On the other hand, Salovey y Mayer [7] divided personal intelligences into five principal capabilities: the knowledge about self-emotions, the capability to control self-emotions, the capability to self-encourage, the recognizing of others emotions, and the control of relationships.

Goleman [9] citing Thomas Pettigrew concludes that emotions related to preconceptions or prejudices formed during childhood. The same author defined that research about prejudices show the need to create a culture more tolerant to others and refuse any form of discrimination or abuse.

The study with forestry engineering students was the conceptual basis in order to find out if prejudices and belief systems would affect the development of emotional skills mainly, during, and after the academic experience with the local communities, or if those emotional skills have not been developed because the lack of social skills [8].

\subsection{Research questions}

Do academic practices, for example recognizing knowledge, beliefs, difficulties and constraints of local communities help the student community to identify and cultivate social or emotional skills?

Do prejudices and preconceived beliefs of forest-engineering students affect the interpersonal relationships developed during academic practices with the local communities?

\subsection{Theoretical framework}

Before the 1980s, theories about intelligence were based on intellectual capacities that were referred to as the psychometric tide that was linked to academic psychology where persons were evaluated using an intellectual quotient (hereafter IQ). The rethinking of these theories recognizes other intelligence dimensions based on new findings from neuroscience, intercultural studies, outputs from different psychological tendencies, and popular beliefs [1].

A pioneer of new intelligence was Gardner [7,9], and Sternberg [10]. The former developed the multi-intelligence theory. The latter developed the Triarquica theory, which supposes that intelligence is three-dimensional. According to Gardner [6], intelligence comprises seven different abilities: linguistic, musical, logic-mathematical, spatial, kinestheticcorporal, and intrapersonal and interpersonal. Damasio [11] made new contributions when he mentioned that the feelings play an important role in our ability to take everyday decisions. Intelligence is not only the ability to reason and learn new concepts, but also the ability to learn about new types of concept [7].

According to Mora and Martin [12], the intelligence concept is a scientific product with a large potential utility. 
Berrocal and Pacheco [13] defined theories of emotional intelligence (EI) such as: 1) the mixed model of Goleman [2], which defined EI as a compendium of stable personality features; competences, social and emotional; and motivational aspects and diverse cognitive abilities. Emotional aptitude is a learned capability based on emotional intelligence. 2) The ability model that was suggested by Mayer and Salovey [14] defined emotional intelligence through four basic abilities: the ability to perceive, give value to and express emotions with precision, seek and produce feelings that facilitate thought, understand emotions, and regulate emotions form emotional and intellectual development.

According to Damasio [11], when people are exposed to new environments, the brain produces a response according to a stimulus. This produces a temporal change in the body and also in the brain structures that maintain thinking. The stimulus as a response can produce a reaction or emotion, for instance: sympathy or compassion. Sympathy must be understood as the possibility to get worried and to understand the suffering of others. Alternatively, if individuals perceive the subjective experience of others, it would result in another emotion called empathy.

Empathy originated from the Greek word "empátheia" that means feeling It demonstrates the capacity to perceive the subject experiences of another. Titehener cited by Goleman [2] enlarged the scope of the concept to denote the type of physical imitation that makes a person confront the others suffering in order to recall identical feelings.

\section{Methodology}

A field trip to the Centro Forestal Tropical (CFT) is conducted each semester for the students of Forestry Engineering from the Universidad del Tolima. CFT is in tropical rain forest, located in the north-west of the Cauca Valley department, (Bajo Calima, Buenaventura).

This CFT is surrounded by afro-colombian communities where livelihoods are based on forest natural resources. This field trip is mandatory for the students in their 10th semester and is comprises of two subjects and four phases: pedagogical agreement, conceptualization, field trip, and final reflection. Also, the field trip is a requirement to conclude professional studies. The student's immersion in this practice was the backdrop to document the information that will be presented in this study.

During the pedagogical agreement, an individual interview was applied to 245 students, in six different groups, to assess their intellectual capacities and also learn about their interests and preferences [15]. In order to get information about emotional abilities, they were asked about their views of rural people and afro-colombian communities.

Interviews were processed and analysed with frequency distribution tables. Initially, this demonstrates the cognitive and emotional abilities of students and contributes to a perception of what capabilities the student has for working with rural communities.

In the conceptualization phase, information about the next topic was provided: rural development, community participation, tools for the dialogue, amongst others. This phase also includes a reflection about stigmas that students have towards the rural societies or ethnic minorities [16]. At this time clear communication and dialogue rules were given for example, respect for community knowledge, the day-to-day life of the community and the difference in culture and beliefs.

In the field trip phase, students were introduced to the community and established a dialogue to know the problems that the community confronts as a society. Students and community discussed possible solutions. The beginning of the field trip was made to get to know the day-to-day practices within the community and to accompany the community in their daily routines. In this way, the field trip used 150 hours (approximately 8 weeks), afterwards the students present the results of their observations and make suggestions for the problems identified. The students also present their findings to the community. After Action Review (AAR) the field trip phase was closed. AAR [17] is a structured discussion where the field trip experience is analysed in relation to objectives, expectations, findings and lessons learned once the field trip was finished. Qualifications for the work and outputs done were given to the students also at the end of the ARR.

Once the field trip finished, the teacher analysed the individual interviews that were applied to students in the pedagogical agreement and also the lessons learned in order to find indications about the manifestation of student emotional skills. For this reason, simple descriptive and frequency statistics for analysing qualitative information was considered. Phrases with meaning of feelings were analysed in order to deduct coincidences according to the concepts and theoretical basis from EI. In this way, it was possible to find out if students developed emotional skills and also the variations in their beliefs or initial prejudices. 


\section{Results and findings}

The results and findings of the student's interviews are presented in Table 1. It is observed than before the beginning of the field trip students from the 10th semester have more cognitive and, technical abilities and skills, than those related to social aspects and emotions (Table 1).

Figure 1 presents the description about social and emotional abilities for six student's groups, which data were considered before and after the field trip experience of the students. The interview questions related with this figure focused on prejudices or beliefs about the black communities and also if students had any previous work experience with communities. According to the comparative analysis, before and after the field trip it was found changes in the opinions and perceptions about the beliefs and prejudices related to the black communities.

Also, the students developed emotional abilities and self-regulation that allowed them to pro-pose collective solutions for the community problems. The field trip experience was the stimulation for the beginning of feelings and empathy about the needs of black communities from this region; environment seems to have provided a flexible social space with multiple opportunities for learning and interacting with others [18].

For instance, one of the six student groups gave results that were collectively found with the community. This was the case for the creation of an NGO called "Sinergia Ecológica Las Brisas", social capital is strengthened by human relationships, in interaction with students favouring cooperation between groups [19].

\subsection{Social and emotional skills learned or expressed before the field trip within the community}

The students were asked about their prejudices and beliefs about the communities of the region. The students accepted having some prejudices, but they did not write them. It is possible that they have the knowledge that these kinds of prejudices are not socially accepted. They only mentioned the expressions as descriptions: i) The people believe that they do not work a lot, ii) they are very happy and love parties, iii) they do nothing to improve their living conditions, iv) they over-use the natural resources, v) they are very demanding for government re-sources and attention, and vi) they are violent. This last stigma is a very commonly held belief because the region has been affected by the Colombian conflict.



Figure 1 A quantitative description of technical knowledge, hobbies, preferences, and emotional and social skills before and after the field trip to the Tropical Forestry Center (CFT) within the community. Bajo Calima, Buenaventura. 
Table 1 Technical knowledges, hobbies, preferences and abilities, and social skills of the forestry students before the beginning of the communitarian participation course.

\begin{tabular}{|c|c|c|c|c|c|}
\hline Technical knowledges & No. & Interests and preferences & No. & $\begin{array}{l}\text { Social skills before } \\
\text { the field trip }\end{array}$ & No. \\
\hline Forestry measurements & 17 & $\begin{array}{l}\text { Musical and cultural } \\
\text { formation }\end{array}$ & 12 & Conflict resolution & 7 \\
\hline Agroforestry & 26 & $\begin{array}{l}\text { Business, entrepreneurship } \\
\text { and sales }\end{array}$ & 5 & $\begin{array}{l}\text { Project } \\
\text { development }\end{array}$ & 2 \\
\hline Silviculture & 11 & $\begin{array}{l}\text { Food technology and } \\
\text { Management }\end{array}$ & 2 & Social work & 4 \\
\hline GIS & 4 & Automotive mechanic & 3 & $\begin{array}{l}\text { Leadership and } \\
\text { motivation }\end{array}$ & 2 \\
\hline Plant forestry & 11 & Risk management & 2 & Anthropology & 2 \\
\hline Mathematics & 13 & English & 11 & Social sciences & 3 \\
\hline Agriculture & 2 & Arts \& crafts & 19 & Customer service & 2 \\
\hline Hydrology & 2 & Carpenter & 5 & & \\
\hline Forestry law & 4 & Recreation and sports: & 26 & & \\
\hline Agroecology & 2 & Waste management & 6 & & \\
\hline Environmental impact & 9 & Nurseries & 7 & & \\
\hline Dendrology & 6 & Literature & 12 & & \\
\hline Photo-interpretation & 3 & Medicinal plants & 2 & & \\
\hline Environmental education & 7 & Theology & 2 & & \\
\hline Forest economics & 2 & $\begin{array}{l}\text { Family planning and } \\
\text { reproductive health }\end{array}$ & 2 & & \\
\hline Computing & 9 & Cooking & 2 & & \\
\hline Conservation & 2 & & & & \\
\hline Forest management & 5 & & & & \\
\hline Soil use and Management & 2 & & & & \\
\hline Physics & 4 & & & & \\
\hline Ecology & 9 & & & & \\
\hline Animal production & 3 & & & & \\
\hline Statistical Software & 5 & & & & \\
\hline Chemistry & 7 & & & & \\
\hline Geology & 2 & & & & \\
\hline Modelling & 5 & & & & \\
\hline Technology of Wood & 3 & & & & \\
\hline Plant physiology & 4 & & & & \\
\hline Watersheds & 5 & & & & \\
\hline
\end{tabular}

Additionally, the characterization and description of the baseline and its following comparison with the final results facilitated the identification of skills for social work with the community. 
Forero- Peña et al. / GSC Advanced Research and Reviews, 2020, 02(03), 036-043

\subsection{Social and emotional skills learned or manifested after field trip within the community}

After the field trip and the deep-thinking exercise with students, phrases were analysed and new expressions were built to reproduce new perceptions that for the exercise were denominated learned lessons [20]. Some expressions are listed below:

I never worked with a community; it was an enriching communication experience. When we communicate with the people, we knew that they have large knowledge that allows them to survive in a difficult environment. I observed big gaps that exist between social sectors at the rural and urban level (health, education, opportunities, among others). I found the community needs very isolated and I feel that I can help. There is a big contradiction: there is no law or support for helping them may be for the isolation, however, I can see that the law is hard and very demanding for the community. Doing and learning is more efficient that reading theories. I found a new skill such as a moderator, leadership because I like the interaction. Because I am very good with organization, I identified situations that were disorganized within the community. I found a receptive community that wants to be successful with projects and that believes in the University. I developed an interest about the community because understood their needs, have confirmed some beliefs and have become cleared it others. The persons are very peaceful and very receptive. I believed that the communication with the community was difficult, but this was a prejudice. It is necessary to create formal spaces and opportunities to interact and talk with people. This time we were beneficial and useful to the community interests. When I had a formal communication, I knew the needs and I wished their expectations were realized. I think I knew their space and that helped me to understand them better.

In other situations, I did not have opportunities to interact with persons of a community and to know their needs. I know that I am able to work in any place and context. I experience the dynamic response when meetings are organized together and also that collective products can produce results in the short term. It is complicated to focus a big group of students and achieve results in the short term. I consider that the group's organization can be prepared from Ibague (Tolima). In this way we will be able to know their background and hence it would be possible to get students involved quicker during field trip activities. We learned from mistakes when things went wrong. There is a need of objectivity: many times, the topics are repetitive, and the facilitator should suggest norms, rules, and limits.

In the phrases review, it was found the use of concept and terms contained feelings and emotions. When for example they wrote that they would like to see a change in the community reality, the students were putting themselves in the other conditions. In a psychological context, this can be interpreted as empathy, it involves trying to understand carefully the nature of an-other person's, their own unique point of view and what meaning this conveys for that individual and reflect regarding our own feelings and thoughts, particularly for emotion management and the ability to communicate [21].

Starting from the definition of intelligence of Sternberg [10], Mora and Martin [12] conclude that if an individual is facing a new problem, without having at least one experience, it voids the possibility of success, so it is necessary to have some cognitive skills that allow them to solve the problem with success. Under this premise, the experience of engineering students with the rural community of Bajo Calima performed an important role in the development of their socioemotional skills, which will allow them to respond positively to new challenges in the future [21]. This learning is going to help them to be more successful in future work as a new professional, mainly in areas related to working with communities and/or in teams.

To give an explanation as to what could have happened, we can take as a reference the hypothesis of Damasio [11] "when we are exposed to new environments, our brain generates a response according to the stimulus, a temporary shift in the body and the brain structures that hold the thought". In this case, study students learned and developed emotions that were generated from an emotionally competent stimulation (EEC), for example the belief that the community involved in the study "suffers or need help". This preconceived belief or stimulus, could express the emotion of sympathy and compassion. Sympathy expressed as worry and under-standing the suffering of others. Perhaps students developed the emotion of empathy when they understood and shared other feelings.

The experience of students with the community of Bajo Calima probably promoted their activation of competent emotional responses, which they had already learned from comparable previous situations or experiences throughout life. Therefore, they probably showed reasoning strategies that required adaptive responses, according to psychological responses of survival and well-being.

Also, the students understood the situation of the people from Bajo Calima community; they agreed that the people have some emotional, affective, and social determinants, (a rationality and ancestral knowledge) ranging beyond the 
possession of logical capacity. This means that they can recognize the emotional intelligence of others [21]. If this is analysed based on the theory of reformulated intelligence [9], students acknowledge and agree, although they do not use the expression, that people who live in rural areas have a kind of intelligence: the naturalistic intelligence.

Students' engagement in the daily activities and work of the members of the community, al-lowed that preconceived beliefs and social prejudices, which students expressed directly or indirectly at the start of the study was changed, similar strategy is recommended by Texeira and Krings [8] to understand interdisciplinary role from the professionals work with communities and vulnerable populations. This method has been used for the past seven years and their prejudices have been modified and the improvement of their social skills has been achieved successfully.

\section{Conclusion}

All variables including academic exercises, experiences in the rural context, combined methodology for the dialogue of knowledge and time spent gave us positive results in the formation of Forest Engineering students in the area of "Community Participation". Interpersonal relationships are crucial to the achievement of individual and collective goals and therefore are essential to developing and learning emotional skills that improve the performance of professionals. Recommendations and Implications for Engineering Future Research Plans. To contribute to the development of social skills, it is recommended to keep field practice for students of Forest Engineering. Moreover, it is recommended that this is institutionalized earlier in the program of studies for Forest Engineering students to develop social skills. Development of socials skills will help students be more empathetic and committed to society, and perhaps, better prepared for developing community projects, especially in post-conflict Colombia. Future research must determine the relationship between emotional intelligence and job performance of forestry-engineering graduates, particularly those that will work with communities. This type of study will involve a causal correlation analysis, using a measuring instruments scale, moreover, the hypothesis should test the existence of a relationship between variables.

\section{Compliance with ethical standards}

\section{Acknowledgments}

The authors thank to all persons from the village Las Brisas and members of the Community Council of the Bajo Calima in Buenaventura, which have contributed unconditionally to training students of forestry engineering of the University of Tolima and many other universities who visit the Tropical Forest Center-TFC. Also to TFC officials who lent us their full support permanently, to each and every one of our students that have contributed to our career as a teacher and professional.

\section{Disclosure of conflict of interest}

Authors hereby state that there is no conflict of interest.

\section{Statement of informed consent}

Informed consent was obtained from all individual participants included in the study.

\section{References}

[1] Olvera L, Dominguez TB and Cruz MA. (2002). Inteligencia emocional. Manual para profesionales en el ámbito individual. Editorial Plaza y Valdes.S.A de C.V, Mexico, 75.

[2] Goleman D. (1995). Emotional Intelligence. Bantam Dell pub group, New York, USA. 413.

[3] Araujo MCy and Leal GM. (2007). Inteligencia Emocional y Desempeño Laboral en las instituciones de educación superior. Revista Arbitraba, 4 (2), 134-147.

[4] Carrasquero R CL. (2010). Aptitudes emocionales que inciden en el aprendizaje organizacional. Revista del Centro de Investigación de Ciencias Administrativas y Gerenciales CICAG Universidad de Zulia, 7(1), 15-30.

[5] Organización de Naciones Unidas para la Educación, la Ciencia y la Cultura. UNESCO. (2002). La Educación Para Todos. Va el mundo por el buen camino? Informe de seguimiento de la EPT en el mundo. París.

[6] Gardner H. (1983). Frames of mind the theory of Multiple Intelligences. New York. Basic Books.

[7] Salovey P and Mayer JD. (1990). Emotional Intelligence. Imagination, Cognition and Personality, 9(3), 185-211. 
[8] Teixeira S and Krings A. (2015). Sustainable Social Work: An Environmental Justice Framework for Social Work Education. Social Work Education, 34(5), 513-527.

[9] Gardner H. (1999). Intelligence Reframed: Multiple Intelligences for the 21 st Century. New York. Basic Books.

[10] Sternberg RJ. (1985). Beyond IQ: A Triarchic Theory of Intelligence. Cambridge: Cambridge University Press.

[11] Damasio A. (2005). En busca de Spinoza. Neurobiología de la emoción y los sentimientos. Crítica. Barcelona. 334.

[12] Mora M JA and Martín J ML. (2007). La concepción de la inteligencia en los planteamientos de Gardner (1983) y Sternberg (1985) como desarrollos teóricos precursores de la noción de inteligencia emocional. Revista de Historia de la Psicología, 28 (4), 67-92.

[13] Berrocal P and Pacheco N. (2005). La Inteligencia Emocional y la educación de las emociones desde el Modelo de Mayer y Salovey. Revista Interuniversitaria de Formación del Profesorado, 19(3), 63-93.

[14] Mayer JD and Salovey P. (1997). What is emotional intelligence? In Salovey P and Sluyter DJ (Eds.), Emotional development and emotional intelligence: Educational implications. Harper Collins, New York, 3-34.

[15] Banco Interamericano de Desarrollo BID. (2011). Pautas para la elaboración de estudios de caso. Vicepresidencia de Sectores y Conocimiento, Departamento de Conocimiento y Aprendizaje (KNL). Washington D.C. 10.

[16] Pino Montoya JW. (2015). Metodología de investigación en la ciencia política: La mirada empírico-analítica. Revista Fundación Universitaria Luis Amigó, 2 (2), 185-195.

[17] Banco Interamericano de Desarrollo BID. (2015). Como identificar y documentar lecciones aprendidas. Vicepresidencia de Sectores y Conocimiento, Departamento de Conocimiento y Aprendizaje (KNL).

[18] Harris F. (2017). The nature of learning at forest school: practitioners' perspective. Education, 45(2), $272-291$.

[19] Yohan L, Rianti IP and Park MS. (2017). Measuring social capital in Indonesian community forest management, Forest Science and Technology, 13(3), 133-141.

[20] Grant L. (2014). Hearts and Minds: Aspects of Empathy and Wellbeing in Social Work Students. Social Work Education, (33)3, 338-352.

\section{How to cite this article}

Forero- Peña LA, Leiva-Rojas EI and Ramírez-Pisco R. (2020). Engineering students enhance their social skills by sharing their knowledge with Afro-Colombian. GSC Advanced Research and Reviews, 2(3), 36-43. 